\title{
NISSEN FUNDOPLICATION IN INFANTS AND CHILDREN: A LONG TERM CLINICAL STUDY
}

\author{
M.M. Abu Zeid \\ Surgery, Gastroentrology Center, Mansoura Universty, Mansoura, Egypt
}

Methodology: Twenty six neurologically normal children (16 boys and 10 girls between 6 months and 11 years old) underwent Nissen fundoplication for intractable or complicated gastroesophageal reflux between October 1982 and February 2002. Before surgery and at follow up visits, all children were subjected to thorough history, barium meal study and gastroscopy with multiple esophageal biopsies. The mean duration of follow up was $68 \pm 64$ months (range: 3 months - 19 years).

Results: Persistent vomiting or regurgitation since birth was the main symptom (24 patients, 92.3\%), chest symptoms occurred in 5 patients $(19.2 \%)$, malnutrition and retarded growth were found in 4 patients (15.4\%), haematemesis and/or melena occurred in 2 patients $(7.7 \%)$ and dysphagia due to esophageal stricture occurred in 4 patients $(15.4 \%)$. There was no mortality. The mean hospital stay was 4.1 days. Twenty two patients $(84.6 \%)$ had no recurrent reflux. Reflux symptoms recurred in 4 cases $(15.4 \%)$. One of these cases had no evidence of recurrent pathological reflux, 2 cases with preoperative stricture developed wrap disruption, recurrent reflux and restricture. Both refused second operation. The fourth case developed melena and reflux esophagitis due to wrap herniation through the hiatus and was successfully managed by second operation.

Conclusion: Nissen fundoplication is an effective operation to correct gastroesophageal reflux in infants and children when the drug therapy fails. The operation should be done before occurrence of complications to decrease the recurrence of reflux. 